\title{
Evolutionary karyotypic theory of cancer versus conventional cancer gene mutation theory
}

\author{
A. A. Stepanenko, V. M. Kavsan \\ Institute of Molecular Biology and Genetics, NAS of Ukraine \\ 150, Zabolotnoho Str., Kyiv, Ukraine, 03680 \\ a.a.stepanenko@gmail.com
}

\begin{abstract}
For decades the conventional gene mutation cancer theory has been postulating that cancer is a genetic disease considered as a result of deterministic sequential accumulation of mutations in the handful of «driver» cancer genes occurring in a continuous linear pattern of cancer progression. However, in contrast to this postulate, recent whole genome and exome sequencing studies of primary tumor bulk and metastases or separate regions withing the same sample have revealed a large number of stochastic gene mutations for each individual with the same cancer type and significant intratumoral genetic heterogeneity with «branched evolutionary tumor growth» or «punctuated clonal evolution without observable intermediate branching» or «no dominant clones in the cancer tissue». Meanwhile, the stochastic karyotypic variation and intratumor heterogeneity are recognized to be the driving force of tumor evolution and major factors in determining relapse with acquired drug resistance. The karyotype evolution/chromosome instability and the resulting magnitude of intratumor heterogeneity significantly correlate with tumorigenic potential of cells, tumor disease progression from precancerous lesions to malignant tumors and metastases, correlate with patient survival, treatment sensitivity, and the risk of acquired resistance. Here, we discuss importance of the evolutionary karyotypic theory in understanding the cancer biology and mechanisms of tumor drug resistance.
\end{abstract}

Keywords: tumor evolution, karyotype, chromosome instability, intratumor heterogeneity, cancer gene, drug resistance.

Introduction. Evidence of tumors has been recorded from molluscs to mammals [1]. There is no correlation between body size, longevity and cancer across species (Peto's paradox), with cancer rates varing twofold, whereas the difference of mammals size reaching a millionfold variation. However, cancer occurs at astonishingly high rates and can be responsible for $20-46 \%$ of total deaths in animals [2]. Cancer is the leading cause of death in economically developed countries and the second leading cause of death in developing countries [3]. Thus, it is justified the increasing financing of tumor biology investigations with especial emphasis on treatment. Nevertheless, as it is stated, «since former US President Richard Nixon declared the «War on Cancer» almost 40 years ago, little progress has been made on reducing the lifetime risk of cancer and increasing survival rates for patients with late-stage diagnoses» [2].

(C) Institute of Molecular Biology and Genetics, NAS of Ukraine, 2012
There is an opinion that «public health initiatives, the introduction of national screening programmes, refinements in operative strategy, reductions in operative mortality and advances in the detection of early cancers, rather than an increase in the efficacy of current anticancer agents, has resulted in the improved survival rates seen in certain solid tumour subtypes» [4]. Indeed, multiple diverse clinic trials have failed to demonstrate effective curable chemotherapy [5-22]. What is the reason for failure?

Evolutionary karyotypic cancer theory. Nowadays, almost all treatment strategies are based on the conventional cancer gene mutation theory, which was postulating for decades that cancer is a genetic disease being considered as a result of deterministic sequential accumulation of mutations in the handful of «driver» cancer genes occurring in a continuous linear pattern of cancer progression [23-28]. However, the recent whole genome and exome sequencing studies of tumor bulk revea- 
led a large number of stochastic gene mutations for each individual with the same cancer type [29-34]. For example, 2576 somatic mutations were identified across 1507 coding genes from 441 tumors comprising breast, lung, ovarian, and prostate cancer types and subtypes [35]. The Network of Cancer Genes (NCG 3.0, http:// bio.ifom-ieo-campus.it/ncg) have collected information on 1494 cancer genes found mutated in 16 different cancer types [33]. The census of cancer genes (http:// www.sanger.ac.uk/genetics/CGP/Census/) includes 487 mutated genes (data on March 2012) manually curated from the scientific literature, which are proved to induce or accelerate cancer development being appropriately changed (point mutations, deletions, translocations or amplifications) (criteria for inclusion in the census of cancer genes are considered in [36]). Meanwhile, the whole exome sequencing of multiple spatially separated samples obtained from the same tumor and metastases followed by phylogenetic reconstruction of tumor progression has revealed significant intratumoral genetic heterogeneity with «no dominant clones in the cancer tissue» [37] or "punctuated clonal evolution ... without observable intermediate branching» [38] or «branched evolutionary tumor growth» with 63 to $69 \%$ of all somatic mutations not detectable across every tumor region and some genes undergoing multiple distinct and spatially separated inactivating mutations within a single tumor [39]. Studies on chronic lymphocytic leukemia have demonstrated that tumor progression can occur in «either a linear or branching manner, with multiple genetic subclones evolving either in succession or in parallel» $[40,41]$. Evaluation of the clonal relationships among pancreatic cancer metastases and primary tumor has led to conclusion that the genetic heterogeneity of metastases reflects heterogeneity already existing within the primary carcinoma, and that the primary carcinoma is a mixture of numerous subclones [42]. Multiregional exome sequencing of prostate cancer has shown the presence of somatically independent tumors within the same prostate [43]. Altogether, these data seriously contradict to the deterministic sequential accumulation of mutations in the handful of «driver» cancer genes occurring in a continuous linear pattern of cancer progression.

Due to inability to find type- and stage-specific recurrent aberrations in solid tumors the multiple diverse numerical and structural chromosome changes in each tumor sample were disregarded and judged as a by-product of transformation by the conventional cancer gene mutation theory [23-28]. However, random aneuploidy/chromosome instability (CIN) and the resulting genomic heterogeneity significantly correlate with tumorigenic potential of cells [44-49], tumor disease progression from precancerous lesions to malignant tumors and then to metastases, patient survival [50-67], intrinsic and acquired (multi)drug resistance [68-84], and radioresistance [85-87]. Interestingly, there is a paradoxical relationship between extreme CIN and improved survival outcome in cancer $[62,88]$. Tumors with extreme CIN display the highest chromosomal structural complexity and chromosomal numerical instability and are associated with improved prognosis relative to tumors with intermediate CIN [88]. It has been shown that missegregation of one or a few chromosomes per division (low CIN) promotes tumorigenesis, whereas missegregation of a larger number of chromosomes per division (high CIN) drives cell death and tumor suppression [89]. When CIN exceeds a certain threshold (in case of extreme CIN), it has a negative impact on cellular fitness [62]. Destabilizing aneuploidy generates nonneoplastic and nonviable cells [90]. Thus, CIN can both promote and constrain tumorigenesis [91-93].

According to the conventional cancer gene mutation theory tumors are addicted to a single activated oncogenic protein or pathway to maintain their malignant properties. Despite a recognized significantly high level of genomic and (epi)genetic heterogeneity within individual tumors, as well as between primary tumors, metastatic cells, and relapses [37-41, 52, 82, 83, 94$109]$, it is believed that acute inactivation of such oncogenic protein or pathway will result in a tumor regression (oncogene addiction concept) [110-117]. However, multiple diverse clinic trials have failed to demonstrate it [5-22].

Duesberg et al. have formulated questions, which the conventional cancer gene mutation theory has not explained: why a single transgene induces diverse cancers with different karyotypes, phenotypes, and complex transcriptomes; why the same transgenes produce conditionally reversible hyperplasias and dysplasias early and irreversible cancers late in conditional transgenic mice models $[76,80]$; why cancer is caused by non- 
mutagenic carcinogens; why cancer develops years to decades after initiation by carcinogens (long latent periods) and follows pre-neoplastic aneuploidy; why cancer is chromosomally and phenotypically unstable, generates much more complex phenotypes than conventional mutation, generates nonselective phenotypes such as metastasis and immortality [23-25]. The conventional genetic theory does not also explain the karyotypic changes that coincide with resistance, the high rates at which cancer cells acquire and enhance resistance compared to the rates of conventional mutation, the wide ranges of resistance such as multidrug resistance, and the frequent occurrence of intrinsic drug resistance [73]. These discrepancies have been explained by the evolutionary karyotypic theory of cancer [26-28, 73, 76, 80, 90, 118-122].

Now it is well documented that prior to the key stages of tumor progression (immortalization, transformation, metastases, and acquisition of drug resistance) a complex dynamic interplay between various stochastic non-clonal and clonal chromosome alterations is observed, and genomic instability and the resulting degree of both clonal and non-clonal heterogeneity are the interconnected driving forces of tumor evolution $[73,80,76$, 119-131]. The magnitude of intratumor heterogeneity correlates with clinical variables such as tumor progression, survival, treatment sensitivity, and the risk of acquired resistance. Moreover, genomic heterogeneity drives phenotypic heterogeneity observed among tumor cells and the evolution of karyotype is accompanied by changes in phenotype $[76,80,101,118,120,132-$ 135]. Genomic instability is associated with profound changes in the transcriptome and proteome. Genomewide analysis of DNA copy number alterations and mRNA expression shows a significant correlation in tumor samples [133, 136-142]. There is also moderate but still significant correlation between the change in global genes copy number and the corresponding proteins level $[143,144]$.

The evolutionary karyotypic theory of cancer has been developed and conceptualized mainly by P. Duesberg's [23-25, 76, 80, 118-120] and H. Heng's groups [26-28, 121, 122, 145, 146]. Studing karyotypic evolution in both individual cells and cell populations during various stages of cellular immortalization process using an in vitro cell culture model Heng's group has re- vealed that karyotypic evolution (macro-evolution) serves as the driving force for immortalization. There are two phases of karyotypic evolution. One is the discontinuous phase characterized by heterogeneous karyotypes within the same and between different passages of culture; the other phase is the stepwise continuous phase within which the majority of cells share similar karyotypes for hundreds of passages. These two phases represent punctuated (or macro-evolution) and Darwinian (or micro) evolution, respectively. Relationship between these two phases and genome system stability, measured by the level of stochastic genome alterations, has shown that the punctuated phase is characterized by genome system instablility (high frequencies of non-clonal chromosome aberrations (NCCAs), whereas the Darwinian stepwise phase demonstrates relative genome system stability (dominant clonal chromosome aberrations (CCAs) and low frequencies of NCCAs). Extremely high genome-level heterogeneity in the punctuated phase provides the genetic underpinning of the high degree of heterogeneity universally detected in cancers. By repeating the same experiments, or analyzing the parallel clones derived from the same initial cell population, it has been documented that the immortalized cells display unique distinctive karyotypes, demonstrating the stochastic nature of karyotypic evolution during cellular immortalization. Follow-up experiments have evidenced that karyotypic evolution can be detected in most of the major transition steps of cancer (immortalization, transformation, metastasis, and drug resistance), and all factors, genetic/non-genetic, internal/external, functioning as a stress to a given system, can contribute to cancer evolution (either through micro- or macroevolution). Further, it has been demonstrated that karyotypic heterogeneity is linked to tumorigenicity. Using six well-characterized in vitro tumor progression models representing various types of cancer including human breast and prostate cancers as well as mouse ovarian cancer it has been shown that all sublines displaying high tumorigenicity, regardless of which molecular mechanisms were detected, are characterized by high levels of genome heterogeneity (the high frequencies of NCCAs). In contrast, all sublines with low tumorigenicity displayed distinctly lower frequencies of NCCAs. Heng et al. describe the evolutionary mechanism of cancer as three components/steps: stresses, the diverse cau- 
ses of cancer, induce genome system instability; this instability produces genetic and epigenetic heterogeneity, which is essential for evolution; somatic cell evolution is based on a series of genome system replacements, which breaks the multiple system constraints (such as the tu mor suppressor function of genome integrity, tissue architecture, and immune system safeguards).

Meanwhile, by analyzing the karyotypes of clonal tumorigenic cell lines, derived from human cells transfected with the same set of artificially activated oncogenes, Duesberg's group has found that different tumorigenic cell lines have individual clonal phenotypes and basically stable karyotypes, although individually variable over many generations in vitro; that the phenotypes and karyotypes of different tumors induced by these lines in different mice, as well as drug-resistant sublines, derived from these lines, are karyotypic and phenotypic variants of the parental prototypes [76]. Stochastic, simultaneous multichromosomal rearrangements of cancer karyotypes generate metastases [120]. Duesberg's group proposed a two-step-mechanism of normal cell transformation to cancer cell [76].

First, carcinogens (mutagenic and nonmutagenic) as well as activated oncogenes trigger random aneuploidy. Aneuploidy destabilizes the karyotype by unbalancing teams of proteins involved in segregation, synthesis, and repair of chromosomes in proportion to the degree of aneuploidy.

Second, aneuploidy initiates and maintains karyotypic evolutions automatically due to the inherent instability of aneuploidy. Most of the newly evolving karyotypes are functionally inferior to those of normal cells or lethal. Occasionally, however, rare cancer-causing karyotypes evolve stochastically. These cancer-causing karyotypes are then stabilized against the inherent instability of aneuploidy by selection for transforming function within narrow clonal limits of variation. The resulting stability within instability of cancer karyotypes explains the flexibility and heterogeneity of cancer genome, which is the basis for the further spontaneous tumor evolution, such as metastasis and drug resistance [76].

Altogether, these findings support the concept that cancer initiation-progression and acquisition of drug resistance represent typical evolutionary processes and karyotypic evolution is the key event in cancer [26, 118-123, 146-153].

\section{Cancer drug resistance: evolution of karyotype.} Multiple mechanisms were proposed to contribute to general drug resistance: changes in transporter proteins, modulation of drug metabolism, enhanced repair of DNA damage, epigenetic mechanisms, tumor microenvironment, the selection of inherently drug refractory cancer stem cell populations or cancer-initiating cells [154-156]. The primary mechanism of acquired resistance during drug or antibody targeted therapy (e. g., inhibition of mutated EGFR, KIT, BRAF, ABL fusion, ALK fusion) proposed by the conventional cancer gene mutation theory of cancer is alterations within the gene that encodes the drug target (e. g., diverse second-site mutations, alternative splicing, gene amplification, and loss of gene rearrangement). Nevertheless, instead of exibiting alterations within the gene that encode the targeted protein the great proportion of tumor samples shows reactivation of the primary signaling pathways through constantly growing list of alternative signaling molecules [154, 157-167]. Moreover, multiple mechanisms of resistance may exist within a single tumor sample at the time of disease progression. According to the evolutionary karyotypic cancer theory karyotypic evolution/CIN is a dominant mechanism in endurement of cells with (multi)drug resistance [73]. Karyotypic evolution/CIN creates genomic, (epi)genetic, and phenotypic heterogeneity, causes global transcriptome and proteome changes, and rewiring of metabolic and signaling networks, altogether, giving rise to diverse drug-resistant variants. CIN is responsible for pre-treatment existance or acquisition during treatment of multiple mechanisms contributing to (multi)drug resistance. It is well documented that CIN significantly correlates with inherent and acquired (multi)drug resistance [68-84] and (multi)drug/chemoresistance acquisition is accompanied by new evolved chromosome imbalances [74, $76,80,81,168-180]$. In support, RNA and protein expression profiles after drug-resistance acquisition differ from parental drug-sensitive cells in expression of tens to thousands genes [174, 179, 181-189]. Acquisition of (multi)drug resistance in budding yeast Saccharomyces cerevisiae [190], human fungal pathogen Candida albicans [191], protozoan parasite Leishmania [192, 193], and Cryptococcus neoformans [194, 195] is also induced by aneuploidy. To the point, aneuploidy in yeast has been shown to provide significant growth ad- 
vantages under severe genetic or environmental perturbations [196]. Even in Escherichia coli multidrug resistance is accompanied by significant changes in metabolism [197]; multiple mutations and substantial changes in gene expression are required to develop high level of resistance for most antibiotics in bacteria [198, 199].

Cytotoxic and targeted drugs used in clinic for standard cancer treatment, for example, such as nocodazole (microtubule-depolymerizing agents), paclitaxel and taxol (microtubule-stabilizing agents), platinum compounds cisplatin and carboplatin (alkylating agents), etoposide and doxorubicin (topoisomerase I and II inhibitors), bleomycin (causes breaks in DNA), actinomycin D (interferes with transcription and replication), 5fluorouracil (thymidylate synthase inhibitor), imatinib and nilotinib (BCR-ABL inhibitors), rapamycin (mTOR inhibitor), and tamoxifen (estrogen receptor inhibitor) induce CIN/aneuploidy in rodent and human cells [74, 118, 168, 169, 200-206]. Drug-mediated stress can foster tumor evolution by both selecting genetic variations and generating novel variations through induction of genome reorganization [122]. Increase in chromosomal aberrations during and after chemotherapy was documented to associate with increased tumor aggressiveness [169, 185, 207, 208] and a higher risk of secondary tumor development [209-214]. Moreover, diverse cytotoxic drugs (e. g., bleomycin, cyclophosphamide, mitomycin $\mathrm{C}$, and procarbazine) cause induction of germ line mutations [200, 209, 215] and transgenerational genome instability in mice $[215,216]$. Targeted therapy (e. g., tyrosine kinase inhibitors) may also affect centrosomes and chromosome stability in disease-unrelated cells or tissues [54, 202-204]. Both cytotoxic and targeted therapies result in the multiple adverse long-term and delayed neurocognitive [217-219] and physical side effects [212, 220-231]. Similarly, antibody therapy has adverse side effects [228, 232-234]. To the point, cancer unrelated drugs are also far beyond safe. One must be concerned by a striking fact that 279 $(52.1 \%)$ out of 530 marketed pharmaceuticals ever tested for carcinogenicity have a positive response in at least one carcinogenicity assay in animals [235].

Thus, based on results of thousands of clinical trials there is no any known chemotherapy (including already clinically tested second generation therapy or syn- thetic lethal therapy) to which resistance of advancedstage tumors would not develop and which would be lack of adverse side effects (fully not investigated and traceable yet but often long-term and delayed) [212, 217-235]. Furthermore, the future of truly effective cancer treatment is endangered by the output of cancer sequencing projects, which revealed hundreds of potential «druggable» targets [30-33]. Statistics says that there are more than 700 new drugs in the clinic, 300 to 500 drugs in development, and more than 10000 clinical trials with 1200 drugs entering phase III studies [236]. All this medicine is still based on the conventional cancer gene mutation theory of cancer.

Perspectives. Human tumors display significant inter- and intratumor heterogeneity in various features including gene expression, gene mutations, epigenetic status, genome alterations, as well as histology, metastatic and proliferative potential. Both cancer sequencing and karyotype evolution/CIN studies strongly support the view that cancer evolution is not the sequential order of genetic alterations (specific cancer genes and common chromosome alterations) but, instead, can be described as «multiple cycles of punctuated and stepwise evolution where stochastic genome-level alterations [not gene mutations] are the key» [28, 122]. Todorovic-Rakovic states, «High-throughput oncogene mutation profiling now reveal all the complexity of cancer and provide the final explanation of the oncogenic pathways, based on stochastic (onco)genomic variation rather than on (onco)genic concepts» [237]. Consequently, the individual genes or pathways in tumors are clinically insignificant due to the unpredictable nature of pathway replacement as a result of genome evolution during cancer progression and upon treatment $[28,122]$. Chemotherapy fails to prolong patient's lives in many cancers with heterogeneous and unstable genomes despite effective initial tumor response [122].

More and more researchers invoke the scentific community to pay attention to tumor evolution, intratumor heterogeneity and changes of intratumor heterogeneity during medical intervention [28, 95, 122, 237-241]. Karyotypic evolution and genomic heterogeneity generate the phenotypic plasticity driving neoplastic progression [28, 119, 122, 239]. There is urgent need to shift from the generally accepted view of cancer as a disease of genes into that of a genome-based disease, 
and from analyzing tumors just as a bulk tissue to as a population of individual tumor cells [28, 122, 237, 238]. These important issues begin to be addressed [37-41, 43, 242].

Acknowledgements. This work was supported in part by National Academy of Sciences of Ukraine in frames of the program «Nanotechnologies and nanomaterials for 2010-2014 years» and by Science and Technology Center in Ukraine, project 5446.

\section{О. А. Степаненко, В. М. Кавсан}

Еволюційна каріотипова теорія раку versus загальновизнаної генної теорії раку

Резюме

Згідно із загальновизнаною генною теорією раку, протягом останніх десятиліть рак вважали генним захворюванням, яке виникає в результаті детерміністичного послідовного накопичення мутаиій у невеликій групі ракових генів, щчо відбувається за лінійной прогресії пухлини. Однак на противагу иььому постулату у недавніх роботах із секвенування геному та екзому первинних пухлин і їхніх метастазів, а також окремих ділянок однієї і тієї ж пухлини виявлено величезну кількість стохастичних генних мутацій у кожній пухлині однакового типу та значну внутрішньопухлинну генетичну гетерогенність з «розгалуженою еволючією росту пухлини» або «переривчастою клональною еволючією без проміжних розгалужень», або «відсутність домінантних клонів у пухлиннії тканині». Стохастичні каріотипові зміни і внутрішньопухлинну гетерогенність визнано провідною силою в еволюиї пухлини і детермінантою розвитку терапевтичної резистентності і рецидиву. Еволюиія каріотипу/хромосомної нестабільності і результуючий рівень внутрішньопухлинної гетерогенності суттєво корелюють з пухлиноутворювальним потенціалом клітин, прогресією пухлини від доброякісної до явно злоякісної та метастазування, а також з виживанням пачієнтів, чутливістю до хіміотерапії і ризиком виникнення резистентності. Обговорюється важливість еволюиійної каріотипової теорї раку у розумінні біології раку і механізмів набуття стійкості до хіміотерапії.

Ключові слова: еволючія пухлини, каріотип, хромосомна нестабільність, внутрішньопухлинна гетерогенність, раковий ген, хіміорезистентність

\section{А. А. Степаненко, В. М. Кавсан}

Эволюционная кариотипическая теория рака versus общепризнанной генной теории рака

\section{Резюме}

Согласно общепризнанной генной теории рака, в течение последних десятилетий рак считали генным заболеванием, возникающим в результате детерминистического последовательного накопления мутаций в небольшой группе раковых генов, происходящего при линейной прогрессии опухоли. Однако в противоположность этому постулату в недавних работах по секвенированию генома и экзома первичных опухолей и их метастазов, а также отдельных участков одной и той же опухоли выявлено огромное количество стохастических генных мутачий в каждой опухоли одного типа и значительную внутриопухолевую генетическую гетерогенность с "разветвленной эволюцией роста опухоли» или «прерывистой клональной эволючией без прослеживаемых промежуточных разветвлений», или «отсутствие доминантных клонов в опухолевой ткани». Стохастические кариотипические изменения и внутриопухолевая гетерогенность признаны ведущей силой в эволюции опухоли и детерминантой развития терапевтической резистентности и рецицива рака. Эволюция кариотипа/ хромосомной нестабильности и результирующий уровень внутриопухолевой гетерогенности существенно коррелируют с опухолеобразующим потенциалом клеток, прогрессией заболевания от преопухолевого доброкачественного к явно злокачественному и метастазированию, а также с выживаемостью пациентов, чувствительностью к химиотерапии и риском приобретения резистентности. Обсуждается важность эволюиионной кариотипической теории в понимании биологии рака и механизмов приобретения стойкости к химиотерапии.

Ключевые слова: эволючия опухоли, кариотип, хромосомная нестабильность, внутриопухолевая гетерогенность, раковый ген, химиорезистентность.

\section{REFERENCES}

1. Leroi A. M., Koufopanou V., Burt A. Cancer selection // Nat. Rev. Cancer.-2003.-3, N 3.-P. 226-231.

2. Caulin A. F., Maley C. C. Peto's Paradox: evolution's prescription for cancer prevention // Trends Ecol. Evol.-2011.-26, N 4.P. 175-182.

3. Jemal A., Bray F., Center M. M., Ferlay J., Ward E., Forman D. Global cancer statistics // CA Cancer J. Clin.-2011.-61, N 2.P. 69-90.

4. Bourke M. G., Salwa S., Harrington K. J., Kucharczyk M. J., Forde P. F., de Kruijf M., Soden D., Tangney M., Collins J. K., $O$ 'Sullivan $G$. C. The emerging role of viruses in the treatment of solid tumours // Cancer Treat. Rev.-2011.-37, N 8.- P. 618-632.

5. Reeder-Hayes K. E., Carey L. A., Sikov W. M. Clinical trials in triple negative breast cancer // Breast Dis.-2010.-32, N 1-2.P. 123-136.

6. Torti D., Trusolino L. Oncogene addiction as a foundational rationale for targeted anti-cancer therapy: promises and perils // EMBO Mol. Med.-2011.-3, N 11.-P. 623-636.

7. Plate J. Clinical trials of vaccines for immunotherapy in pancreatic cancer // Expert Rev. Vaccines.-2011.-10, N 6.-P. 825-836.

8. Brookman-May S., Burger M., Wieland W. F., Rossler W., May $M$., Denzinger $S$. Vaccination therapy in renal cell carcinoma: current position and future options in metastatic and localized disease // Expert Rev. Vaccines.-2011.-10, N 6.-P. 837-852.

9. Leffers N., Daemen T., Boezen H. M., MeliefK. J., Nijman H. W. Vaccine-based clinical trials in ovarian cancer // Expert Rev. Vaccines.-2011.-10, N 6.-P. 775-784.

10. Santarpia M., Altavilla G., Salazar M. F., Magri I., Pettineo G., Benecchi S., Rosell R. Tyrosine kinase inhibitors for non-smallcell lung cancer: finding patients who will be responsive // Expert Rev. Respir. Med.-2011.-5, N 3.-P. 413-424.

11. Yoong J., Michael M., Leong T. Targeted therapies for gastric cancer: current status // Drugs.-2011.-71, N 11.-P. 1367-1384.

12. Blank C. U., Hooijkaas A. I., Haanen J. B., Schumacher T. N. Combination of targeted therapy and immunotherapy in melanoma // Cancer Immunol. Immunother.-2011.-60, N 10.-P. 1359-1371.

13. Coppin C., Kollmannsberger C., Le L., Porzsolt F., Wilt T. J. Targeted therapy for advanced renal cell cancer (RCC): a Cochrane systematic review of published randomised trials // BJU Int.-2011.-108, N 10.-P. 1556-1563. 
14. Banerjee $S$., Kaye $S$. The role of targeted therapy in ovarian cancer // Eur. J. Cancer.-2011.-47, Suppl 3.-S116-130.

15. Higgins M. J., Baselga J. Targeted therapies for breast cancer // J. Clin. Invest.-2011.-121, N 10.-P. 3797-3803.

16. Pujade-Lauraine E., Alexandre J. Update of randomized trials in recurrent disease // Ann. Oncol.-2011.-22, Suppl. 8.-P. viii61viii64.

17. Leung M., Rosen D., Fields S., Cesano A., Budman D. R. Poly (ADP-ribose) polymerase-1 inhibition: preclinical and clinical development of synthetic lethality // Mol. Med.-2011.-17, N 78.-P. 854-862.

18. Jansen M. H., van Vuurden D. G., Vandertop W. P., Kaspers G. J. Diffuse intrinsic pontine gliomas: a systematic update on clinical trials and biology // Cancer Treat. Rev.-2012.-38, N 1.-P. 27-35.

19. Perez-Lorenzo R., Zheng B. Targeted inhibition of BRAF kinase: opportunities and challenges for therapeutics in melanoma // Biosci. Rep.-2012.-32, N 1.-P. 25-33.

20. Singer E. A., Gupta G. N., Srinivasan R. Targeted therapeutic strategies for the management of renal cell carcinoma // Curr. Opin. Oncol.-2012.-24, N 3.-P. 284-290.

21. Mackey J. R., Kerbel R. S., Gelmon K. A., McLeod D. M., Chia S. K., Rayson D., Verma S., Collins L. L., Paterson A. H., Robidoux A., Pritchard K. I. Controlling angiogenesis in breast cancer: A systematic review of anti-angiogenic trials // Cancer Treat. Rev.-2012.-38, N 6.-P. 637-688

22. Chan S. L., Yeo W. Targeted therapy of hepatocellular carcinoma: present and future // J. Gastroenterol. Hepatol.-2012.-27, N 5.-P. 862-872.

23. Duesberg P., Fabarius A., Hehlmann R. Aneuploidy, the primary cause of the multilateral genomic instability of neoplastic and preneoplastic cells // IUBMB Life.-2004.-56, N 2.-P. 65-81.

24. Duesberg P., Li R., Fabarius A., Hehlmann R. The chromosomal basis of cancer // Cell Oncol.-2005.-27, N 5-6.-P. 293-318.

25. Duesberg P., Li R., Fabarius A., Hehlmann R. Aneuploidy and cancer: from correlation to causation // Contrib. Microbiol.2006.-13.-P. 16-44.

26. Heng H. H., Stevens J. B., Liu G., Bremer S. W., Ye K. J., Reddy P. V., Wu G. S., Wang Y. A., Tainsky M. A., Ye C. J. Stochastic cancer progression driven by non-clonal chromosome aberrations // J. Cell. Physiol.-2006.-208, N 2.-P. 461-472.

27. Heng H. H., Bremer S. W., Stevens J. B., Ye K. J., Liu G., Ye C. J. Genetic and epigenetic heterogeneity in cancer: a genome-centric perspective // J. Cell. Physiol.-2009.-220, N 3.-P. 538-547.

28. Heng H. H., Stevens J. B., Bremer S. W., Ye K. J., Liu G., Ye C. J. The evolutionary mechanism of cancer // J. Cell. Biochem.2010.-109, N 6.-P. 1072-1084.

29. Fox E. J., Salk J. J., Loeb L. A. Cancer genome sequencing - an interim analysis // Cancer Res.-2009.-69, N 12.-P. 4948-4950.

30. Ciccarelli F. D. The (r)evolution of cancer genetics // BMC Biol.-2010.-8.-P. 74

31. Syed A. S., D'Antonio M., Ciccarelli F. D. Network of Cancer Genes: a web resource to analyze duplicability, orthology and network properties of cancer genes // Nucleic Acids Res.2010.-38.-D670-675.

32. Bessarabova M., Pustovalova O., Shi W., Serebriyskaya T., Ishkin A., Polyak K., Velculescu V. E., Nikolskaya T., Nikolsky Y. Functional synergies yet distinct modulators affected by genetic alterations in common human cancers // Cancer Res.-2011.-71, N 10.-P. 3471-3481.

33. D'Antonio M., Pendino V., Sinha S., Ciccarelli F. D. Network of Cancer Genes (NCG 3.0): integration and analysis of genetic and network properties of cancer genes // Nucleic Acids Res.2012.-40.-D978-983.
34. Loeb L. A. Human cancers express mutator phenotypes: origin, consequences and targeting // Nat. Rev. Cancer.-2011.-11, N 6.P. $450-457$.

35. Kan Z., Jaiswal B. S., Stinson J., Janakiraman V., Bhatt D., Stern H. M., Yue P., Haverty P. M., Bourgon R., Zheng J., Moorhead M., Chaudhuri S., Tomsho L. P., Peters B. A., Pujara K., Cordes S., Davis D. P., Carlton V. E., Yuan W., Li L., Wang W., Eigenbrot C., Kaminker J. S., Eberhard D. A., Waring P., Schuster S. C., Modrusan Z., Zhang Z., Stokoe D., de Sauvage F. J., Faham M., Seshagiri $S$. Diverse somatic mutation patterns and pathway alterations in human cancers // Nature.-2010.-466, N 7308.-P. 869-873.

36. Futreal P. A., Coin L., Marshall M., Down T., Hubbard T., Wooster R., Rahman N., Stratton M. R. A census of human cancer genes // Nat. Rev. Cancer.-2004.-4, N 3.-P. 177-183.

37. Xu X., Hou Y., Yin X., Bao L., Tang A., Song L., Li F., Tsang S., $W u K$., Wu H., He W., Zeng L., Xing M., Wu R., Jiang H., Liu X., Cao D., Guo G., Hu X., Gui Y., Li Z., Xie W., Sun X., Shi M., Cai Z., Wang B., Zhong M., Li J., Lu Z., Gu N., Zhang X., Goodman L., Bolund L., Wang J., Yang H., Kristiansen K., Dean M., Li Y., Wang $J$. Single-cell exome sequencing reveals single-nucleotide mutation characteristics of a kidney tumor // Cell.-2012.148, N 5.-P. 886-895.

38. Navin N., Kendall J., Troge J., Andrews P., Rodgers L., McIndoo J., Cook K., Stepansky A., Levy D., Esposito D., Muthuswamy L., Krasnitz A., McCombie W. R., Hicks J., Wigler M. Tumour evolution inferred by single-cell sequencing // Nature.-2011.-472, N 7341.-P. 90-94.

39. Gerlinger M., Rowan A. J., Horswell S., Larkin J., Endesfelder D., Gronroos E., Martinez P., Matthews N., Stewart A., Tarpey P., Varela I., Phillimore B., Begum S., McDonald N. Q., Butler A., Jones D., Raine K., Latimer C., Santos C. R., Nohadani M., Eklund A. C., Spencer-Dene B., Clark G., Pickering L., Stamp G., Gore M., Szallasi Z., Downward J., Futreal P. A., Swanton C. Intratumor heterogeneity and branched evolution revealed by multiregion sequencing // N. Engl. J. Med.-2012.-366, N 10.- P. 883892.

40. Knight S. J., Yau C., Clifford R., Timbs A. T., Akha E. S., Dreau H. M., Burns A., Ciria C., Oscier D. G., Pettitt A. R., Dutton S., Holmes C. C., Taylor J., Cazier J. B., Schuh A. Quantification of subclonal distributions of recurrent genomic aberrations in paired pre-treatment and relapse samples from patients with B-cell chronic lymphocytic leukemia // Leukemia.-2012. doi: 10. 1038/leu.2012.13

41. Braggio E., Kay N. E., Vanwier S., Tschumper R. C., Smoley S., Eckel-Passow J. E., Sassoon T., Barrett M., Van Dyke D. L., Byrd J. C., Jelinek D. F., Shanafelt T. D., Fonseca R. Longitudinal genome wide analysis of patients with chronic lymphocytic leukemia reveals complex evolution of clonal architecture at disease progression and at the time of relapse // Leukemia.2012. doi: 10.1038/leu.2012.14

42. Yachida S., Jones S., Bozic I., Antal T., Leary R., Fu B., Kamiyama M., Hruban R. H., Eshleman J. R., Nowak M. A., Velculescu V. E., Kinzler K. W., Vogelstein B., Iacobuzio-Donahue C. A. Distant metastasis occurs late during the genetic evolution of pancreatic cancer // Nature.-2010.-467, N 7319.-P. 1114-1117.

43. Lindberg J., Klevebring D., Liu W., Neiman M., Xu J., Wiklund P., Wiklund F., Mills I. G., Egevad L., Gronberg H. Exome sequencing of prostate cancer supports the hypothesis of independent tumour origins // Eur. Urol.-2012. doi: 10.1016/j.bbr. 2011.03.031.

44. Bartholdi M. F., Ray F. A., Cram L. S., Kraemer P. M. Karyotype instability of Chinese hamster cells during in vivo tumor progression // Somat. Cell. Mol. Genet.-1987.-13, N 1.-P. 1-10. 
45. Miura M., Miura Y., Padilla-Nash H. M., Molinolo A. A., Fu B., Patel V., Seo B. M., Sonoyama W., Zheng J. J., Baker C. C., Chen $W$., Ried T., Shi S. Accumulated chromosomal instability in murine bone marrow mesenchymal stem cells leads to malignant transformation // Stem Cells.-2006.-24, N 4.-P. 1095-1103.

46. Ragel B. T., Couldwell W. T., Gillespie D. L., Wendland M. M., Whang K., Jensen R. L. A comparison of the cell lines used in meningioma research // Surg. Neurol.-2008.-70, N 3.-P. 295-307.

47. Marella N. V., Malyavantham K. S., Wang J., Matsui S., Liang $P$., Berezney $R$. Cytogenetic and cDNA microarray expression analysis of MCF10 human breast cancer progression cell lines // Cancer Res.-2009.-69, N 14.-P. 5946-5953.

48. Blum B., Benvenisty N. The tumorigenicity of diploid and aneuploid human pluripotent stem cells // Cell Cycle.- 2009.-8, N 23.P. 3822-3830.

49. Sotillo R., Schvartzman J. M., Socci N. D., Benezra R. Mad2-induced chromosome instability leads to lung tumour relapse after oncogene withdrawal // Nature.-2010.-464, N 7287.-P. 436-440.

50. Zitzelsberger H., Engert D., Walch A., Kulka U., Aubele M., Hofler H., Bauchinger M., Werner M. Chromosomal changes during development and progression of prostate adenocarcinomas // Br. J. Cancer.-2001.-84, N 2.-P. 202-208.

51. Veltman J. A., van Weert I., Aubele M., Bot F. J., Ramaekers F. C., Manni J. J., Hopman A. H. Specific steps in aneuploidization correlate with loss of heterozygosity of $9 \mathrm{p} 21,17 \mathrm{p} 13$ and $18 \mathrm{q} 21$ in the progression of pre-malignant laryngeal lesions // Int. J. Cancer--2001.-91, N 2.-P. 193-199.

52. Aubele M., Auer G., Braselmann H., Nahrig J., Zitzelsberger H., Quintanilla-Martinez L., Smida J., Walch A., Hofler H., Werner $M$. Chromosomal imbalances are associated with metastasis-free survival in breast cancer patients // Anal. Cell. Pathol.-2002.-24, N 2-3.-P. 77-87.

53. Pihan G. A., Wallace J., Zhou Y., Doxsey S. J. Centrosome abnormalities and chromosome instability occur together in preinvasive carcinomas // Cancer Res.-2003.-63, N 6.-P. 13981404.

54. Giehl M., Fabarius A., Frank O., Hochhaus A., Hafner M., Hehlmann R., Seifarth $W$. Centrosome aberrations in chronic myeloid leukemia correlate with stage of disease and chromosomal instability // Leukemia.-2005.-19, N 7.-P. 1192-1197.

55. Gorgoulis V. G., Vassiliou L. V., Karakaidos P., Zacharatos P., Kotsinas A., Liloglou T., Venere M., Ditullio R. A. Jr., Kastrinakis N. G., Levy B., Kletsas D., Yoneta A., Herlyn M., Kittas C., Halazonetis T. D. Activation of the DNA damage checkpoint and genomic instability in human precancerous lesions // Nature.2005.-434, N 7035.-P. 907-913.

56. Jonkers Y. M., Claessen S. M., Perren A., Schmid S., Komminoth P., Verhofstad A. A., Hofland L. J., de Krijger R. R., Slootweg P. $J$., Ramaekers F. C., Speel E. J. Chromosomal instability predicts metastatic disease in patients with insulinomas // Endocr. Relat. Cancer.-2005.-12, N 2.-P. 435-447.

57. Li X., Galipeau P. C., Sanchez C. A., Blount P. L., Maley C. C., Arnaudo J., Peiffer D. A., Pokholok D., Gunderson K. L., Reid B. $J$. Single nucleotide polymorphism-based genome-wide chromosome copy change, loss of heterozygosity, and aneuploidy in Barrett's esophagus neoplastic progression // Cancer. Prev. Res. (Phila).-2008.-1, N 6.-P. 413-423.

58. Loncarevic I. F., Hering A., Posorski N., Linden T., Hoyer H., Bucsky P. Number of genomic imbalances correlates with the overall survival for adrenocortical cancer in childhood // Pediatr. Blood Cancer.-2008.-51, N 3.-P. 356-362.

59. Paulson T. G., Maley C. C., Li X., Li H., Sanchez C. A., Chao D. L., Odze R. D., Vaughan T. L., Blount P. L., Reid B. J. Chromosomal instability and copy number alterations in Barrett's eso- phagus and esophageal adenocarcinoma // Clin. Cancer Res.2009.-15, N 10.-P. 3305-3314.

60. Sheffer M., Bacolod M. D., Zuk O., Giardina S. F., Pincas H., Barany F., Paty P. B., Gerald W. L., Notterman D. A., Domany E. Association of survival and disease progression with chromosomal instability: a genomic exploration of colorectal cancer // Proc. Natl Acad. Sci. USA.-2009.-106, N 17.-P. 7131-7136.

61. Heilig C. E., Loffler H., Mahlknecht U., Janssen J. W., Ho A. D., Jauch A., Kramer A. Chromosomal instability correlates with poor outcome in patients with myelodysplastic syndromes irrespectively of the cytogenetic risk group // J. Cell Mol. Med.2010.-14, N 4.-P. 895-902.

62. Roylance R., Endesfelder D., Gorman P., Burrell R. A., Sander J., Tomlinson I., Hanby A. M., Speirs V., Richardson A. L., Birkbak N. J., Eklund A. C., Downward J., Kschischo M., Szallasi Z., Swanton $C$. Relationship of extreme chromosomal instability with long-term survival in a retrospective analysis of primary breast cancer // Cancer Epidemiol. Biomarkers Prev.-2011.-20, N 10.-P. 2183-2194.

63. Endesfelder D., McGranahan N., Birkbak N. J., Szallasi Z., Kschischo M., Graham T. A., Swanton C. A breast cancer meta-analysis of two expression measures of chromosomal instability reveals a relationship with younger age at diagnosis and high risk histopathological variables // Oncotarget.-2011.-2, N 7.-P. 529-537.

64. Smid M., Hoes M., Sieuwerts A. M., Sleijfer S., Zhang Y., Wang Y., Foekens J. A., Martens $J$. W. Patterns and incidence of chromosomal instability and their prognostic relevance in breast cancer subtypes // Breast Cancer Res. Treat.-2011.-128, N 1.P. 23-30.

65. Lagarde P., Perot G., Kauffmann A., Brulard C., Dapremont V., Hostein I., Neuville A., Wozniak A., Sciot R., Schoffski P., Aurias A., Coindre J. M., Debiec-Rychter M., Chibon F. Mitotic checkpoints and chromosome instability are strong predictors of clinical outcome in gastrointestinal stromal tumors // Clin. Cancer Res.-2011.-18, N 3.-P. 826-838.

66. Bakhoum S. F., Danilova O. V., Kaur P., Levy N. B., Compton D. $A$. Chromosomal instability substantiates poor prognosis in patients with diffuse large B-cell lymphoma // Clin. Cancer Res.2011.-17, N 24.-P. 7704-7711.

67. Ylipaa A., Hunt K. K., Yang J., Lazar A. J., Torres K. E., Lev D. C., Nykter M., Pollock R. E., Trent J., Zhang W. Integrative genomic characterization and a genomic staging system for gastrointestinal stromal tumors // Cancer.-2011.-117, N 2.-P. 380-389.

68. Hata H., Matsuzaki H., Yoshida M., Sonoki T., Kuribayashi N., Nagasaki A., Kimura T., Harada N., Takatsuki K. Hyperdiploid myeloma cell as an indicator of poor prognosis and drug refractoriness // Int. J. Hematol.-1997.-66, N 2.-P. 219-226.

69. Zwaan C. M., Kaspers G. J., Pieters R., Hahlen K., Huismans D. R., Zimmermann M., Harbott J., Slater R. M., Creutzig U., Veerman A. J. Cellular drug resistance in childhood acute myeloid leukemia is related to chromosomal abnormalities // Blood.-2002.100, N 9.-P. 3352-3360.

70. Weise A., Liehr T., Efferth T., Kuechler A., Gebhart E. Comparative M-FISH and CGH analyses in sensitive and drug-resistant human T-cell acute leukemia cell lines // Cytogenet. Genome Res.2002.-98, N 2-3.-P. 118-125.

71. Hattinger C. M., Reverter-Branchat G., Remondini D., Castellani G. C., Benini S., Pasello M., Manara M. C., Scotlandi K., Picci P., Serra $M$. Genomic imbalances associated with methotrexate resistance in human osteosarcoma cell lines detected by comparative genomic hybridization-based techniques // Eur. J. Cell. Biol.-2003.-82, N 9.-P. 483-493.

72. Akervall J., Guo X., Qian C. N., Schoumans J., Leeser B., Kort E., Cole A., Resau J., Bradford C., Carey T., Wennerberg J., An- 
derson H., Tennvall J., Teh B. T. Genetic and expression profiles of squamous cell carcinoma of the head and neck correlate with cisplatin sensitivity and resistance in cell lines and patients // Clin. Cancer Res.-2004.-10, N 24.-P. 8204-8213.

73. Duesberg P., Li R., Sachs R., Fabarius A., Upender M. B., Hehlmann $R$. Cancer drug resistance: the central role of the karyotype // Drug Resist. Updat.-2007.-10, N 1-2.-P. 51-58.

74. Bouchet B. P., Bertholon J., Falette N., Audoynaud C., Lamblot C., Puisieux A., Galmarini C. M. Paclitaxel resistance in untransformed human mammary epithelial cells is associated with an aneuploidy-prone phenotype // Br. J. Cancer.-2007.-97, N 9.P. $1218-1224$

75. Davis E., Teng H., Bilican B., Parker M. I., Liu B., Carriera S., Goding C. R., Prince $S$. Ectopic Tbx 2 expression results in polyploidy and cisplatin resistance // Oncogene.-2008.-27, N 7.P. 976-984.

76. Nicholson J. M., Duesberg P. On the karyotypic origin and evolution of cancer cells // Cancer Genet. Cytogenet.-2009.-194, N 2.-P. 96-110.

77. Swanton C., Nicke B., Schuett M., Eklund A. C., Ng C., Li Q., Hardcastle T., Lee A., Roy R., East P., Kschischo M., Endesfelder D., Wylie P., Kim S. N., Chen J. G., Howell M., Ried T., Habermann J. K., Auer G., Brenton J. D., Szallasi Z., Downward J. Chromosomal instability determines taxane response // Proc. Natl Acad. Sci. USA.-2009.-106, N 21.-P. 8671-8676.

78. McClelland S. E., Burrell R. A., Swanton C. Chromosomal instability: a composite phenotype that influences sensitivity to chemotherapy // Cell Cycle.-2009.-8, N 20.-P. 3262-3266.

79. Gerlinger M., Swanton C. How Darwinian models inform therapeutic failure initiated by clonal heterogeneity in cancer medicine // Br. J. Cancer.-2010.-103, N 8.-P. 1139-1143.

80. Klein A., Li N., Nicholson J. M., McCormackA. A., Graessmann $A$., Duesberg $P$. Transgenic oncogenes induce oncogene-independent cancers with individual karyotypes and phenotypes // Cancer Genet. Cytogenet.-2010.-200, N 2.-P. 79-99.

81. Bacher U., Haferlach T., Alpermann T., Zenger M., Kroger N., Beelen D. W., Kern W., Schnittger S., Haferlach C. Comparison of cytogenetic clonal evolution patterns following allogeneic hematopoietic transplantation versus conventional treatment in patients at relapse of AML // Biol. Blood Marrow Transplant.2010.-16, N 12.-P. 1649-1657.

82. Cooke S. L., Ng C. K., Melnyk N., Garcia M. J., Hardcastle T., Temple J., Langdon S., Huntsman D., Brenton J. D. Genomic analysis of genetic heterogeneity and evolution in high-grade serous ovarian carcinoma // Oncogene.-2010.-29, N 35.-P. 4905-4913.

83. Cooke S. L., Temple J., Macarthur S., Zahra M. A., Tan L. T., Crawford R. A., Ng C. K., Jimenez-Linan M., Sala E., Brenton J. $D$. Intra-tumour genetic heterogeneity and poor chemoradiotherapy response in cervical cancer // Br. J. Cancer.-2011.-104, N 2.-P. 361-368.

84. Lee A. J., Endesfelder D., Rowan A. J., Walther A., Birkbak N. J., Futreal P. A., Downward J., Szallasi Z., Tomlinson I. P., Howell M., Kschischo M., Swanton C. Chromosomal instability confers intrinsic multidrug resistance // Cancer Res.-2011.-71, N 5.P. $1858-1870$

85. Morgan W. F., Murnane J. P. A role for genomic instability in cellular radioresistance? // Cancer Metastasis Rev.-1995.-14, N 1.P. 49-58.

86. Limoli C. L., Corcoran J. J., Jordan R., Morgan W. F., Schwartz $J$. L. A role for chromosomal instability in the development of and selection for radioresistant cell variants // Br. J. Cancer.-2001.84, N 4.-P. 489-492.

87. Fernandez-L. A., Squatrito M., Northcott P., Awan A., Holland E. C., Taylor M. D., Nahle Z., Kenney A. M. Oncogenic YAP pro- motes radioresistance and genomic instability in medulloblastoma through IGF2-mediated Akt activation // Oncogene.-2011.31, N 15.-P. 1923-1937.

88. Birkbak N. J., Eklund A. C., Li Q., McClelland S. E., Endesfelder D., Tan P., Tan I. B., Richardson A. L., Szallasi Z., Swanton C. Paradoxical relationship between chromosomal instability and survival outcome in cancer // Cancer Res.-2011.-71, N 10.P. 3447-3452.

89. Weaver B. A., Silk A. D., Cleveland D. W. Low rates of aneuploidy promote tumorigenesis while high rates of aneuploidy cause cell death and tumor suppression // Cell. Oncol.-2008.--30, N 5.P. 453.

90. Li L., McCormack A. A., Nicholson J. M., Fabarius A., Hehlmann R., Sachs R. K., Duesberg P. H. Cancer-causing karyotypes: chromosomal equilibria between destabilizing aneuploidy and stabilizing selection for oncogenic function // Cancer Genet. Cytogenet.-2009.-188, N 1.-P. 1-25.

91. Weaver B. A., Cleveland D. W. The aneuploidy paradox in cell growth and tumorigenesis // Cancer Cell.-2008.-14, N 6.P. 431-433.

92. Weaver B. A., Cleveland D. $W$. The role of aneuploidy in promoting and suppressing tumors // J. Cell Biol.-2009.-185, N 6.P. 935-937.

93. Sheltzer J. M., Amon A. The aneuploidy paradox: costs and benefits of an incorrect karyotype // Trends Genet.-2011.-27, N 11.P. 446-453.

94. Nobusawa S., Lachuer J., Wierinckx A., Kim Y. H., Huang J., Legras $C$., Kleihues $P$., Ohgaki $H$. Intratumoral patterns of genomic imbalance in glioblastomas // Brain Pathol.-2010.-20, N 5.P. 936-944.

95. Almendro V., Fuster $G$. Heterogeneity of breast cancer: etiology and clinical relevance // Clin. Transl. Oncol.-2011.-13, N 11.P. 767-773.

96. Ruiz C., Lenkiewicz E., Evers L., Holley T., Robeson A., Kiefer J., Demeure M. J., Hollingsworth M. A., Shen M., Prunkard D., Rabinovitch P. S., Zellweger T., Mousses S., Trent J. M., Carpten J. D., Bubendorf L., Von Hoff D., Barrett M. T. Advancing a clinically relevant perspective of the clonal nature of cancer // Proc. Natl Acad. Sci. USA.-2011.-108, N 29.-P. 12054-12059.

97. Siegmund K. D., Marjoram P., Tavare S., Shibata D. High DNA methylation pattern intratumoral diversity implies weak selection in many human colorectal cancers // PLoS One.-2011.-6, N 6.- 21657.

98. MalekJ. A., Mery E., Mahmoud Y. A., Al-Azwani E. K., Roger L., Huang R., Jouve E., Lis R., Thiery J. P., Querleu D., Rafii A. Copy number variation analysis of matched ovarian primary tumors and peritoneal metastasis // PLoS One.-2011.-6, N 12.-e28561.

99. Snuderl M., Fazlollahi L., Le L. P., Nitta M., Zhelyazkova B. H., Davidson C. J., Akhavanfard S., Cahill D. P., Aldape K. D., Betensky R. A., Louis D. N., Iafrate A.J. Mosaic amplification of multiple receptor tyrosine kinase genes in glioblastoma // Cancer Cell.-2011.-20, N 6.-P. 810-817.

100. Hogan L. E., Meyer J. A., Yang J., Wang J., Wong N., Yang W., Condos G., Hunger S. P., Raetz E., Saffery R., Relling M. V., Bhojwani D., Morrison D. J., Carroll W. L. Integrated genomic analysis of relapsed childhood acute lymphoblastic leukemia reveals therapeutic strategies // Blood.-2011.-118, N 19.-P. 5218-5226.

101. Buob D., Fauvel H., Buisine M. P., Truant S., Mariette C., Porchet N., Wacrenier A., Copin M. C., Leteurtre E. The complex intratumoral heterogeneity of colon cancer highlighted by laser microdissection// Dig. Dis. Sci.-2011.-57, N 5.-P. 1271-1280.

102. Korshunov A., Remke M., Kool M., Hielscher T., Northcott P. A., Williamson D., Pfaff E., Witt H., Jones D. T., Ryzhova M., Cho Y. J., Wittmann A., Benner A., Weiss W. A., von Deimling A., 
Scheurlen W., Kulozik A. E., Clifford S. C., Peter Collins V., Westermann F., Taylor M. D., Lichter P., Pfister S. M. Biological and clinical heterogeneity of MYCN-amplified medulloblastoma // Acta Neuropathol.-2012.-123, N 4.-P. 515-527.

103. Samuel N., Hudson T. J. The molecular and cellular heterogeneity of pancreatic ductal adenocarcinoma // Nat. Rev. Gastroenterol. Hepatol.-2011.-9, N 2.-P. 77-87.

104. Anderson K., Lutz C., van Delft F. W., Bateman C. M., Guo Y., Colman S. M., Kempski H., Moorman A. V., Titley I., Swansbury J., Kearney L., Enver T., Greaves M. Genetic variegation of clonal architecture and propagating cells in leukaemia // Nature.2011.-469, N 7330.-P. 356-361.

105. Gunnarsson R., Mansouri L., Isaksson A., Goransson H., Cahill N., Jansson M., Rasmussen M., Lundin J., Norin S., Buhl A. M., Smedby K. E., Hjalgrim H., Karlsson K., Jurlander J., Geisler $C$., Juliusson G., Rosenquist $R$. Array-based genomic screening at diagnosis and during follow-up in chronic lymphocytic leukemia // Haematologica.-2011.-96, N 8.-P. 1161-1169.

106. Kloosterman W. P., Hoogstraat M., Paling O., Tavakoli-Yaraki M., Renkens I., Vermaat J. S., van Roosmalen M. J., van Lieshout S., Nijman I. J., Roessingh W., van't Slot R., van de Belt J., Guryev $V$., Koudijs M., Voest E., Cuppen E. Chromothripsis is a common mechanism driving genomic rearrangements in primary and metastatic colorectal cancer // Genome Biol.-2011.-12, N 10.-R103.

107. Russnes H. G., Navin N., Hicks J., Borresen-Dale A. L. Insight into the heterogeneity of breast cancer through next-generation sequencing // J. Clin. Invest.-2011.-121, N 10.-P. 3810-3818.

108. Seol H., Lee H. J., Choi Y., Lee H. E., Kim Y. J., Kim J. H., Kang E., Kim S. W., Park S. Y. Intratumoral heterogeneity of HER2 gene amplification in breast cancer: its clinicopathological significance// Mod. Pathol.-2012. Doi: 10.1038/modpathol.2012.36.

109. Wu X., Northcott P. A., Dubuc A., Dupuy A. J., Shih D. J., Witt H., Croul S., Bouffet E., Fults D. W., Eberhart C. G., Garzia L., Van Meter T., Zagzag D., Jabado N., Schwartzentruber J., Majewski J., Scheetz T. E., Pfister S. M., Korshunov A., Li X. N., Scherer S. W., Cho Y. J., Akagi K., MacDonald T. J., Koster J., McCabe M. G., Sarver A. L., Collins V. P., Weiss W. A., Largaespada D. A., Collier L. S., Taylor M. D. Clonal selection drives genetic divergence of metastatic medulloblastoma // Nature.-2012.-482, N 7386.-P. 529-533.

110. Giuriato S., Felsher D. W. How cancers escape their oncogene habit // Cell Cycle.-2003.-2, N 4.-P. 329-332.

111. Jonkers J., Berns A. Oncogene addiction: sometimes a temporary slavery // Cancer Cell.-2004.-6, N 6.-P. 535-538.

112. Sharma S. V., Fischbach M. A., Haber D. A., Settleman J. «Oncogenic shock»: explaining oncogene addiction through differential signal attenuation // Clin. Cancer Res.-2006.-12, N 14, Pt 2.-4392s-4395s.

113. Sharma S. V., Settleman J. Oncogene addiction: setting the stage for molecularly targeted cancer therapy // Genes Dev.-2007.21, N 24.-P. 3214-3231.

114. Weinstein I. B., Joe A. Oncogene addiction // Cancer Res.-2008.68, N 9.-P. 3077-3080.

115. Mc Cormick F. Cancer therapy based on oncogene addiction // J. Surg. Oncol.-2011.-103, N 6.-P. 464-467.

116. Yan $W$., Zhang $W$., Jiang T. Oncogene addiction in gliomas: implications for molecular targeted therapy // J. Exp. Clin. Cancer Res.-2011.-30.-P. 58.

117. Settleman J. Oncogene addiction // Curr. Biol.-2012.-22, N 2.R43-44.

118. Fabarius A., Li R., Yerganian G., Hehlmann R., Duesberg P. Specific clones of spontaneously evolving karyotypes generate individuality of cancers // Cancer Genet. Cytogenet.-2008.-180, N 2.-P. 89-99.
119. Duesberg P., Mandrioli D., McCormack A., Nicholson J. M. Is carcinogenesis a form of speciation? // Cell Cycle.-2011.-10, N 13.-P. 2100-2114.

120. Duesberg P., Iacobuzio-Donahue C., Brosnan J. A., McCormack A., Mandrioli D., Chen L. Origin of metastases: Subspecies of cancers generated by intrinsic karyotypic variations // Cell Cycle.2012.-11, N 6.-P. 1151-1166.

121. Heng H. H., Liu G., Stevens J. B., Bremer S. W., Ye K. J., Ye C. J. Genetic and epigenetic heterogeneity in cancer: the ultimate challenge for drug therapy // Curr. Drug Targets.-2010.-11, N 10.-P. 1304-1316.

122. Heng H. H., Stevens J. B., Bremer S. W., Liu G., Abdallah B. Y., $Y e$ C. J. Evolutionary mechanisms and diversity in cancer // Adv. Cancer Res.-2011.-112.-P. 217-253.

123. Merlo L. M., Pepper J. W., Reid B. J., Maley C. C. Cancer as an evolutionary and ecological process // Nat. Rev. Cancer.-2006.6, N 12.-P. 924-935.

124. Maley C. C., Galipeau P. C., Finley J. C., Wongsurawat V. J., Li X., Sanchez C. A., Paulson T. G., Blount P. L., Risques R. A., Rabinovitch P. S., Reid B. J. Genetic clonal diversity predicts progression to esophageal adenocarcinoma // Nat. Genet.-2006.38, N 4.-P. 468-473.

125. Shibata D. Clonal diversity in tumor progression // Nat. Genet.2006.-38, N 4.-P. 402-403.

126. Lyons J. G., Lobo E., Martorana A. M., Myerscough M. R. Clonal diversity in carcinomas: its implications for tumour progression and the contribution made to it by epithelial-mesenchymal transitions // Clin. Exp. Metastasis.-2008.-25, N 6.-P. 665-677.

127. Klein C. A. Parallel progression of primary tumours and metastases // Nature Rev. Cancer.-2009.-9, N 4.-P. 302-312.

128. Park S. Y., Gonen M., Kim H. J., Michor F., Polyak K. Cellular and genetic diversity in the progression of in situ human breast carcinomas to an invasive phenotype // J. Clin. Invest.-2010.120, N 2.-P. 636-644.

129. Graham T. A., McDonald S. A. Genetic diversity during the development of Barrett's oesophagus-associated adenocarcinoma: how, when and why? // Biochem. Soc. Trans.-2010.-38, N 2.P. 374-379.

130. Merlo L. M., Shah N. A., Li X., Blount P. L., Vaughan T. L., Reid B. J., Maley C. C. A comprehensive survey of clonal diversity measures in Barrett's esophagus as biomarkers of progression to esophageal adenocarcinoma // Cancer Prev. Res. (Phila).-2010.-3, N 11.-P. 1388-1397.

131. Greaves M., Maley C. C. Clonal evolution in cancer // Nature.2012.- 481, N 7381.-P. 306-313.

132. Davey P., Rauth A. M., Mason L., Addy L. Spontaneous phenotypic and karyotypic progression in the SV40 transfected cell line SVG during prolonged passage in vitro // J. Neurooncol.1990.-8, N 1.-P. 13-22.

133. Gao C., Furge K., Koeman J., Dykema K., Su Y., Cutler M. L., Werts A., Haak P., Vande Woude G. F. Chromosome instability, chromosome transcriptome, and clonal evolution of tumor cell populations // Proc. Natl Acad. Sci. USA.-2007.-104, N 21.P. 8995-9000.

134. Geyer F. C., Weigelt B., Natrajan R., Lambros M. B., de Biase D., Vatcheva R., Savage K., Mackay A., Ashworth A., Reis-Filho J. $S$. Molecular analysis reveals a genetic basis for the phenotypic diversity of metaplastic breast carcinomas // J. Pathol.-2010.220, N 5.-P. 562-573.

135. Kalisky T., Blainey P., Quake S. R. Genomic analysis at the single-cell level // Annu. Rev. Genet.-2011.-45.-P. 431-445.

136. Bussey K. J., Chin K., Lababidi S., Reimers M., Reinhold W. C., Kuo W. L., Gwadry F., Ajay J., Kouros-Mehr H., Fridlyand J., Jain A., Collins C., Nishizuka S., Tonon G., Roschke A., Gehl- 
haus K., Kirsch I., Scudiero D. A., Gray J. W., Weinstein J. N. Integrating data on DNA copy number with gene expression levels and drug sensitivities in the NCI-60 cell line panel // Mol. Cancer Ther.-2006.-5, N 4.-P. 853-867.

137. Yoshimoto T., Matsuura K., Karnan S., Tagawa H., Nakada C., Tanigawa M., Tsukamoto Y., Uchida T., Kashima K., Akizuki S., Takeuchi I., Sato F., Mimata H., Seto M., Moriyama M. High-resolution analysis of DNA copy number alterations and gene expression in renal clear cell carcinoma // J. Pathol.-2007.-213, N 4.-P. 392-401.

138. Tsukamoto Y., Uchida T., Karnan S., Noguchi T., Nguyen L. T., Tanigawa M., Takeuchi I., Matsuura K., Hijiya N., Nakada C., Kishida T., Kawahara K., Ito H., Murakami K., Fujioka T., Seto M., Moriyama M. Genome-wide analysis of DNA copy number alterations and gene expression in gastric cancer // J. Pathol.2008.-216, N 4.-P. 471-482.

139. Jung S. H., Shin S. H., Yim S. H., Choi H. S., Lee S. H., Chung Y. J. Integrated analysis of copy number alteration and RNA expression profiles of cancer using a high-resolution whole-genome oligonucleotide array // Exp. Mol. Med.-2009.-41, N 7.-P. 462-470.

140. Kadota M., Yang H. H., Gomez B., Sato M., Clifford R. J., Meerzaman D., Dunn B. K., Wakefield L. M., Lee M. P. Delineating genetic alterations for tumor progression in the MCF10A series of breast cancer cell lines // PLoS One.-2010.-5, N 2.-e9201.

141. Ortiz-Estevez M., De Las Rivas J., Fontanillo C., Rubio A. Segmentation of genomic and transcriptomic microarrays data reveals major correlation between DNA copy number aberrations and gene-loci expression // Genomics.-2011.-97, N 2.-P. 86-93.

142. Huang N., Shah P. K., Li C. Lessons from a decade of integrating cancer copy number alterations with gene expression profiles // Brief Bioinform.-2012.-13, N 3.-P. 305-316

143. Geiger T., Cox J., Mann M. Proteomic changes resulting from gene copy number variations in cancer cells // PLoS Genet.-2010.6, N 9.-e1001090.

144. Valsesia A., Rimoldi D., Martinet D., Ibberson M., Benaglio P., Quadroni M., Waridel P., Gaillard M., Pidoux M., Rapin B., Rivolta C., Xenarios I., Simpson A. J., Antonarakis S. E., Beckmann J. S., Jongeneel C. V., Iseli C., Stevenson B. J. Networkguided analysis of genes with altered somatic copy number and gene expression reveals pathways commonly perturbed in metastatic melanoma // PLoS One.-2011.-6, N 4.-e18369.

145. Heng H. H., Liu G., Stevens J. B., Bremer S. W., Ye K. J., Ye C. J. Genetic and epigenetic heterogeneity in cancer: the ultimate challenge for drug therapy // Curr. Drug Targets.-2010.-11, N 10.P. 1304-1316.

146. Ye C. J., Stevens J. B., Liu G., Bremer S. W., Jaiswal A. S., Ye K. J., Lin M. F., Lawrenson L., Lancaster W. D., Kurkinen M., Liao J. D., Gairola C. G., Shekhar M. P., Narayan S., Miller F. R., Heng H. H. Genome based cell population heterogeneity promotes tumorigenicity: the evolutionary mechanism of cancer // J. Cell Physiol.-2009.-219, N 2.-P. 288-300.

147. Crespi B., Summers K. Evolutionary biology of cancer // Trends Ecol. Evol.-2005.-20, N 10.-P. 545-552.

148. Greaves M. Darwinian medicine: a case for cancer // Nat. Rev. Cancer.-2007.-7, N 3.-P. 213-221.

149. Marusyk A., DeGregori J. Declining cellular fitness with age promotes cancer initiation by selecting for adaptive oncogenic mutations // Biochim. Biophys. Acta.-2008.-1785, N 1.-P. 1-11.

150. Merlo L. M., Wang L. S., Pepper J. W., Rabinovitch P. S., Maley C. C. Polyploidy, aneuploidy and the evolution of cancer// Adv. Exp. Med. Biol.-2010.-676.-P. 1-13.

151. Vincent $M . D$. The animal within: carcinogenesis and the clonal evolution of cancer cells are speciation events sensu stricto // Evolution.-2010.-64, N 4.-P. 1173-1183.
152. Vincent M. D. Cancer: beyond speciation // Adv. Cancer Res.2011.-112.-P. 283-350.

153. Gatenby R. A., Gillies R. J., Brown J. S. Of cancer and cave fish // Nat. Rev. Cancer.-2011.-11, N 4.-P. 237-238.

154. Roychowdhury S., Talpaz M. Managing resistance in chronic myeloid leukemia // Blood Rev.-2011.-25, N 6.-P. 279-290.

155. Rosenzweig $S$. A. Acquired resistance to drugs targeting receptor tyrosine kinases // Biochem. Pharmacol.-2011.-83, N 8.P. 1041-1048.

156. Palakurthi S., Yellepeddi V. K., Vangara K. K. Recent trends in cancer drug resistance reversal strategies using nanoparticles // Expert. Opin. Drug Deliv.-2012.-9, N 3.-P. 287-301.

157. Pao W., Chmielecki J. Rational, biologically based treatment of EGFR-mutant non-small-cell lung cancer // Nat. Rev. Cancer.2010.-10, N 11.-P. 760-774.

158. Mehra R., Serebriiskii I. G., Dunbrack R. L. Jr., Robinson M. K., Burtness B., Golemis E. A. Protein-intrinsic and signaling network-based sources of resistance to EGFR- and ErbB familytargeted therapies in head and neck cancer // Drug Resist. Updat.2011.-14, N 6.-P. 260-279.

159. Carter C. A., Giaccone G. Treatment of nonsmall cell lung cancer: overcoming the resistance to epidermal growth factor receptor inhibitors // Curr. Opin. Oncol.-2012.-24, N 2.P. 123-129.

160. Brand T. M., Iida M., Wheeler D. L. Molecular mechanisms of resistance to the EGFR monoclonal antibody cetuximab // Cancer Biol. Ther.-2011.-11, N 9.-P. 777-792.

161. Fiszman G. L., Jasnis M. A. Molecular mechanisms of trastuzumab resistance in HER2 overexpressing breast cancer // Int. J. Breast Cancer.-2011.-2011.-Doi:10.4061/2011/352182.

162. Rezvani A. R., Maloney D. G. Rituximab resistance // Best. Pract. Res. Clin. Haematol.-2011.-24, N 2.-P. 203-216.

163. Jazirehi A. R., Bonavida B. Development of rituximab-resistant B-NHL clones: an in vitro model for studying tumor resistance to monoclonal antibody-mediated immunotherapy // Methods Mol. Biol.-2011.-731.-P. 407-419.

164. Garrett J. T., Arteaga C. L. Resistance to HER2-directed antibodies and tyrosine kinase inhibitors: mechanisms and clinical implications // Cancer Biol. Ther.-2011.-11, N 9.-P. 793-800.

165. Lovly C. M., Pao W. Escaping ALK inhibition: mechanisms of and strategies to overcome resistance // Sci. Transl. Med.-2012.4, N 120.-P. 120ps2.

166. Alcala A. M., Flaherty K. T. BRAF inhibitors for the treatment of metastatic melanoma: clinical trials and mechanisms of resistance // Clin. Cancer Res.-2012.-18, N 1.-P. 33-39.

167. Little A. S., Balmanno K., Sale M. J., Smith P. D., Cook S. J. Tumour cell responses to MEK1/2 inhibitors: acquired resistance and pathway remodelling // Biochem. Soc. Trans.-2012.-40, N 1.-P. 73-78.

168. Hochhaus A., Kreil S., Corbin A. S., La Rosee P., Muller M. C., Lahaye T., Hanfstein B., Schoch C., Cross N. C., Berger U., Gschaidmeier H., Druker B. J., Hehlmann R. Molecular and chromosomal mechanisms of resistance to imatinib (STI571) therapy // Leukemia.-2002.-16, N 11.-P. 2190-2196.

169. Kotchetkov R., Cinatl J., Blaheta R., Vogel J. U., Karaskova J., Squire J., Hernaiz Driever P., Klingebiel T., Cinatl J. Jr. Development of resistance to vincristine and doxorubicin in neuroblastoma alters malignant properties and induces additional karyotype changes: a preclinical model // Int. J. Cancer.2003.-104, N 1.-P. 36-43.

170. Hu Y., Pang E., Lai P. B., Squire J. A., MacGregor P. F., Beheshti B., Albert M., Leung T. W., Wong N. Genetic alterations in doxorubicin-resistant hepatocellular carcinoma cells: a combined study of spectral karyotyping, positional expression pro- 
filing and candidate genes // Int. J. Oncol.-2004.-25, N 5.P. 1357-1364

171. Pang E., Hu Y., Chan K. Y., Lai P. B., Squire J. A., Macgregor P. F., Beheshti B., Albert M., Leung T. W., Wong N. Karyotypic imbalances and differential gene expressions in the acquired doxorubicin resistance of hepatocellular carcinoma cells // Lab. Invest.-2005.-85, N 5.-P. 664-674.

172. Swords R., Quinn J., Fay M., O'Donnell R., Goldman J., Murphy $P$. T. CML clonal evolution with resistance to single agent imatinib therapy // Clin. Lab. Haematol.-2005.-27, N 5.-P. 347349.

173. Zaccaria A., Valenti A. M., Donti E., Gozzetti A., Ronconi S., Spedicato $F$. Persistence of chromosomal abnormalities additional to the Philadelphia chromosome after Philadelphia chromosome disappearance during imatinib therapy for chronic myeloid leukemia // Haematologica.-2007.-92, N 4.-P. 564-565.

174. Rosenhahn J., Weise A., Michel S., Hennig K., Hartmann I., Schiefner J., Schubert K., Liehr T., von Eggeling F., Loncarevic I. F. Cytogenetic characterisation and proteomic profiling of the Imatinib-resistant cell line KCL22-R // Int. J. Oncol.-2007.-31, N 1.-P. 121-128.

175. Whittington P. J., Piechocki M. P., Heng H. H., Jacob J. B., Jones R. F., Back J. B., Wei W. Z. DNA vaccination controls Her-2 ${ }^{+}$ tumors that are refractory to targeted therapies // Cancer Res.2008.-68, N 18.-P. 7502-7511.

176. Yamamoto K., Yakushijin K., Nishikawa S., Minagawa K., Katayama Y., Shimoyama M., Matsui T. Imatinib resistance in a novel translocation der(17)t $(1 ; 17)(\mathrm{q} 25 ; \mathrm{p} 13)$ with loss of TP53 but without BCR/ABL kinase domain mutation in chronic myelogenous leukemia // Cancer Genet. Cytogenet.-2008.-183, N 1.P. 77-81.

177. Dencic-Fekete M., Dordevic V., Storlazzi C.T., Jankovic G., Bogdanovic A., Jovanovic J., Rocchi M., Todoric-Zivanovic B., Strnad M., Gotic M. t $(5 ; 6 ; 12)$ associated with resistance to imatinib mesylate in chronic myeloid leukemia // Int. J. Hematol.2009.-89, N 4.-P. 508-512.

178. Yuan J., Shah R., Kulharya A., Ustun C. Near-tetraploidy clone can evolve from a hyperdiploidy clone and cause resistance to lenalidomide and bortezomib in a multiple myeloma patient // Leuk. Res.-2010.-34, N 7.-P. 954-957.

179. Hashemi J., Worrall C., Vasilcanu D., Fryknas M., Sulaiman L., Karimi M., Weng W. H., Lui W. O., Rudduck C., Axelson M., Jernberg-Wiklund H., Girnita L., Larsson O., Larsson C. Molecular characterization of acquired tolerance of tumor cells to picropodophyllin (PPP) // PLoS One.-2011.-6, N 3.-e14757.

180. Tegze B., Szallasi Z., Haltrich I., Penzvalto Z., Toth Z., Liko I., Gyorffy B. Parallel evolution under chemotherapy pressure in 29 breast cancer cell lines results in dissimilar mechanisms of resistance // PLoS One.-2012.-7, N 2.-e30804.

181. Michaelis M., Rothweiler F., Barth S., Cinatl J., van Rikxoort M., Loschmann N., Voges Y., Breitling R., von Deimling A., Rodel F., Weber K., Fehse B., MackE., Stiewe T., Doerr H. W., Speidel $D$., Cinatl J. Jr. Adaptation of cancer cells from different entities to the MDM2 inhibitor nutlin-3 results in the emergence of p53-mutated multi-drug-resistant cancer cells // Cell Death Dis.2011.-2.-e243.

182. Kuramitsu Y., Taba K., Ryozawa S., Yoshida K., Zhang X., Tanaka T., Maehara S., Maehara Y., Sakaida I., Nakamura K. Identification of up- and down-regulated proteins in gemcitabineresistant pancreatic cancer cells using two-dimensional gel electrophoresis and mass spectrometry // Anticancer Res.-2010.-30, N 9.-P. 3367-3372.

183. Yoshida K., Kuramitsu Y., Murakami K., Ryozawa S., Taba K., Kaino S., Zhang X., Sakaida I., Nakamura K. Proteomic diffe- rential display analysis for TS-1-resistant and -sensitive pancreatic cancer cells using two-dimensional gel electrophoresis and mass spectrometry // Anticancer Res.-2011.-31, N 6.-P. 21032108.

184. Chen Y. W., Liu J. Y., Lin S. T., Li J. M., Huang S. H., Chen J. Y., Wu J. Y., Kuо C. C., Wu C. L., Lu Y. C., Chen Y. H., Fan C. Y., Huang P. C., Law C. H., Lyu P. C., Chou H. C., Chan H. L. Proteomic analysis of gemcitabine-induced drug resistance in pancreatic cancer cells // Mol. Biosyst.-2011.-7, N 11.-P. 3065-3074.

185. Ong P. S., Chan S. Y., Ho P. C. Microarray analysis revealed dysregulation of multiple genes associated with chemoresistance to $\mathrm{As}(2) \mathrm{O}(3)$ and increased tumor aggressiveness in a newly established arsenic-resistant ovarian cancer cell line, OVCAR-3/AsR // Eur. J. Pharm. Sci.-2011.-45, N 3.-P. 367-378.

186. Kars M. D., Iseri O. D., Gunduz U. A microarray based expression profiling of paclitaxel and vincristine resistant MCF-7 cells // Eur. J. Pharmacol.-2011.-657, N 1-3.-P. 4-9.

187. Iseri O. D., Kars M. D., Arpaci F., Atalay C., PakI., Gunduz U. Drug resistant MCF-7 cells exhibit epithelial-mesenchymal transition gene expression pattern // Biomed. Pharmacother.-2011.65, N 1.-P. 40-45.

188. Iseri O. D., Kars M. D., Gunduz U. Two different docetaxel resistant MCF-7 sublines exhibited different gene expression pattern // Mol. Biol. Rep.-2012.-39, N 4.-P. 3505-3516.

189. Mutlu P., Ural A. U., Gunduz U. Differential gene expression analysis related to extracellular matrix components in drug-resistant RPMI-8226 cell line // Biomed. Pharmacother.-2012.66, N 3.-P. 228-231.

190. Chen G., Bradford W. D., Seidel C. W., Li R. Hsp90 stress potentiates rapid cellular adaptation through induction of aneuploidy // Nature.-2012.-482, N 7384.-P. 246-250.

191. Selmecki A. M., Dulmage K., Cowen L. E., Anderson J. B., Berman $J$. Acquisition of aneuploidy provides increased fitness during the evolution of antifungal drug resistance // PLoS Genet.-2009.5, N 10.-e1000705.

192. Ubeda J. M., Legare D., Raymond F., Ouameur A. A., Boisvert S., Rigault P., Corbeil J., Tremblay M. J., Olivier M., Papadopoulou B., Ouellette M. Modulation of gene expression in drug resistant Leishmania is associated with gene amplification, gene deletion and chromosome aneuploidy // Genome Biol.-2008.-9, N 7.-R115.

193. Leprohon P., Legare D., Raymond F., Madore E., Hardiman G., Corbeil J., Ouellette M. Gene expression modulation is associated with gene amplification, supernumerary chromosomes and chromosome loss in antimony-resistant Leishmania infantum // Nucleic Acids Res.-2009.-37, N 5.-P. 1387-1399.

194. Sionov E., Lee H., Chang Y. C., Kwon-Chung K. J. Cryptococcus neoformans overcomes stress of azole drugs by formation of disomy in specific multiple chromosomes // PLoS Pathog.-2010.6, N 4.-e1000848.

195. Semighini C. P., Averette A. F., Perfect J. R., Heitman J. Deletion of Cryptococcus neoformans AIF ortholog promotes chromosome aneuploidy and fluconazole-resistance in a metacaspaseindependent manner // PLoS Pathog.-2011.-7, N 11.-e1002364.

196. Pavelka N., Rancati G., Li R. Dr Jekyll and Mr Hyde: role of aneuploidy in cellular adaptation and cancer// Curr. Opin. Cell. Biol.-2010.-22, N 6.-P. 809-815.

197. Piras C., Soggiu A., Bonizzi L., Gaviraghi A., Deriu F., De Martino L., Iovane G., Amoresano A., Roncada P. Comparative proteomics to evaluate multi drug resistance in Escherichia coli // Mol. Biosyst.-2011.-8, N 4.-P. 1060-1067.

198. Toprak E., Veres A., Michel J. B., Chait R., Hartl D. L., Kishony R. Evolutionary paths to antibiotic resistance under dynamically sustained drug selection // Nat. Genet.-2011.-44, N 1.-P. 101-105. 
199. Sass A., Marchbank A., Tullis E., Lipuma J. J., Mahenthiralingam $E$. Spontaneous and evolutionary changes in the antibiotic resistance of Burkholderia cenocepacia observed by global gene expression analysis // BMC Genomics.-2011.-12.-P. 373.

200. Jackson M. A., Stack H. F., Waters M. D. Genetic activity profiles of anticancer drugs // Mutat. Res.-1996.-355, N 1-2.-P. 171208.

201. Bonatti S., Simili M., Benedetti P. A., Morandi F., Menichini P., Del Carratore R., Barale R., Abbondandolo A. Altered centrosomes in ataxia-telangiectasia cells and rapamycin-treated Chinese hamster cells // Environ. Mol. Mutagen.-2005.-46, N 3.P. 164-173.

202. Fabarius A., Giehl M., Frank O., Spiess B., Zheng C., Muller M. C., Weiss C., Duesberg P., Hehlmann R., Hochhaus A., Seifarth $W$. Centrosome aberrations after nilotinib and imatinib treatment in vitro are associated with mitotic spindle defects and genetic instability // Br. J. Haematol.-2007.-138, N 3.-P. 369-373.

203. Fabarius A., Giehl M., Rebacz B., Kramer A., Frank O., Haferlach C., Duesberg P., Hehlmann R., Seifarth W., Hochhaus A. Centrosome aberrations and $\mathrm{G}_{1}$ phase arrest after in vitro and in vivo treatment with the SRC/ABL inhibitor dasatinib // Haematologica.-2008.-93, N 8.-P. 1145-1154.

204. Goncalves E. M., Ventura C. A., Yano T., Rodrigues Macedo M. L., Genari S. C. Morphological and growth alterations in Vero cells transformed by cisplatin // Cell Biol. Int.-2006.-30, N 6.P. 485-494.

205. Bueno C., Catalina P., Melen G. J., Montes R., Sanchez L., Ligero G., Garcia-Perez J. L., Menendez P. Etoposide induces MLL rearrangements and other chromosomal abnormalities in human embryonic stem cells // Carcinogenesis.-2009.-30, N 9.- P. 16281637.

206. Zacharaki P., Stephanou G., Demopoulos N. A. Comparison of the aneugenic properties of nocodazole, paclitaxel and griseofulvin in vitro. Centrosome defects and alterations in protein expression profiles // J. Appl. Toxicol.-2012. Doi: 10.1002/jat.2745.

207. Mujoo K., Zhang L., Klostergaard J., Donato N. J. Emergence of cisplatin-resistant cells from the OVCAR-3 ovarian carcinoma cell line with p53 mutations, altered tumorigenicity, and increased apoptotic sensitivity to $p 53$ gene replacement // Int. J. Gynecol. Cancer.-2000.-10, N 2.-P. 105-114.

208. Blaheta R. A., Daher F. H., Michaelis M., Hasenberg C., Weich E. M., Jonas D., Kotchetkov R., Doerr H. W., Cinatl J. Jr. Chemoresistance induces enhanced adhesion and transendothelial penetration of neuroblastoma cells by down-regulating NCAM surface expression // BMC Cancer.-2006.-6.-P. 294.

209. Lopez de Mesa R., Lopez de Cerain Salsamendi A., Ariznabarreta L. S., Calasanz Abinzano M. J., Patino-Garcia A. Measurement and analysis of the chemotherapy-induced genetic instability in pediatric cancer patients // Mutagenesis.-2002.-17, N 2.P. 171-175.

210. Hijiya N., Hudson M. M., Lensing S., Zacher M., Onciu M., Behm F. G., Razzouk B. I., Ribeiro R. C., Rubnitz J. E., Sandlund J. T., Rivera G. K., Evans W. E., Relling M. V., Pui C. H. Cumulative incidence of secondary neoplasms as a first event after childhood acute lymphoblastic leukemia // JAMA.-2007.-297, N 11.-P. 1207-1215.

211. Meadows A. T., Friedman D. L., Neglia J. P., Mertens A. C., Donaldson S. S., Stovall M., Hammond S., Yasui Y., Inskip P. D. Second neoplasms in survivors of childhood cancer: findings from the Childhood Cancer Survivor Study cohort // J. Clin. Oncol.-2009.-27, N 14.-P. 2356-2362.

212. Arnault J. P., Wechsler J., Escudier B., Spatz A., Tomasic G., Sibaud V., Aractingi S., Grange J. D., Poirier-Colame V., Malka D., Soria J. C., Mateus C., Robert C. Keratoacanthomas and squamous cell carcinomas in patients receiving sorafenib // J. Clin. Oncol.-2009.-27, N 23.-e59-61.

213. Witt K. L., Bishop J. B. Mutagenicity of anticancer drugs in mammalian germ cells // Mutat. Res.-1996.-355, N 1-2.-P. 209-234.

214. Chandrakasan S., Ye C. J., Chitlur M., Mohamed A. N., Rabah R., Konski A., Heng H. H., Savagan S. Malignant fibrous histiocytoma two years after autologous stem cell transplant for Hodgkin lymphoma: evidence for genomic instability // Pediatr. Blood Cancer.-2011.-56, N 7.-P. 1143-1145.

215. Glen C. D., Smith A. G., Dubrova Y. E. Single-molecule PCR analysis of germ line mutation induction by anticancer drugs in mice // Cancer Res.-2008.-68, N 10.-P. 3630-3636.

216. Glen C. D., Dubrova Y. E. Exposure to anticancer drugs can result in transgenerational genomic instability in mice // Proc. Natl Acad. Sci. USA.-2012.-109, N 8.-P. 2984-2988.

217. Correa D. D., Ahles T. A. Neurocognitive changes in cancer survivors // Cancer J.-2008.-14, N 6.-P. 396-400.

218. Fardell J. E., Vardy J., Johnston I. N., Winocur G. Chemotherapy and cognitive impairment: treatment options // Clin. Pharmacol. Ther.-2011.-90, N 3.-P. 366-376.

219. Janelsins M. C., Kohli S., Mohile S. G., Usuki K., Ahles T.A., Morrow G. R. An update on cancer- and chemotherapy-related cognitive dysfunction: current status // Semin. Oncol.-2011.38, N 3.-P. 431-438.

220. Hartmann J. T., Haap M., Kopp H. G., Lipp H. P. Tyrosine kinase inhibitors - a review on pharmacology, metabolism and side effects // Curr. Drug Metab.-2009.-10, N 5.-P. 470-481.

221. Amitay-Laish I., Stemmer S. M., Lacouture M. E. Adverse cutaneous reactions secondary to tyrosine kinase inhibitors including imatinib mesylate, nilotinib, and dasatinib // Dermatol. Ther.-2011.-24, N 4.-P. 386-395.

222. Min J. H., Lee H. Y., Lim H., Ahn M. J., Park K., Chung M. P., Lee $K$. $S$. Drug-induced interstitial lung disease in tyrosine kinase inhibitor therapy for non-small cell lung cancer: a review on current insight // Cancer Chemother. Pharmacol.-2011.-68, N 5.-P. 1099-1109.

223. Blake-Haskins J. A., Lechleider R. J., Kreitman R. J. Thrombotic microangiopathy with targeted cancer agents // Clin. Cancer Res.-2011.-17, N 18.-P. 5858-5866.

224. Ravaud A. Treatment-associated adverse event management in the advanced renal cell carcinoma patient treated with targeted therapies // Oncologist.-2011.-16, Suppl. 2.-P. 32-44.

225. Walraven M., Witteveen P. O., Lolkema M. P., van Hillegersberg R., Voest E. E., Verheul H. M. Antiangiogenic tyrosine kinase inhibition related gastrointestinal perforations: a case report and literature review // Angiogenesis.-2011.-14, N 2.-P. 135-141.

226. Eschenhagen T., Force T., Ewer M. S., de Keulenaer G. W., Suter T. M., Anker S. D., Avkiran M., de Azambuja E., Balligand J. L., Brutsaert D. L., Condorelli G., Hansen A., Heymans S., Hill J. A., Hirsch E., Hilfiker-Kleiner D., Janssens $S$., de Jong $S$., Neubauer G., Pieske B., Ponikowski P., Pirmohamed M., Rauchhaus M., Sawyer D., Sugden P. H., Wojta J., Zannad F., Shah A. $M$. Cardiovascular side effects of cancer therapies: a position statement from the heart failure association of the european society of cardiology // Eur. J. Heart Fail.-2011.-13, N 1.-P. 1-10.

227. Salie R., Silver R. T. Uncommon or delayed adverse events associated with imatinib treatment for chronic myeloid leukemia // Clin. Lymphoma Myeloma Leuk.-2010.-10, N 5.-P. 331335.

228. Bonny M., Buyse V., Brochez L. Dermatological side effects of current and upcoming targeted therapies in oncology // Acta Clin. Belg.-2011.-66, N 2.-P. 97-103.

229. Witteles R. M., Fowler M. B., Telli M. L. Chemotherapyassociated cardiotoxicity: how often does it really occur and 
how can it be prevented? // Heart Fail Clin.-2011.-7, N 3.P. 333-344.

230. Grover S., Hill-Kayser C. E., Vachani C., Hampshire M. K., Dilullo G. A., Metz J. M. Patient reported late effects of gynecological cancer treatment // Gynecol. Oncol.-2012.-124, N 3.P. 399-403.

231. Gutzmer R., Wollenberg A., Ugurel S., Homey B., Ganser A., Kapp $A$. Cutaneous side effects of new antitumor drugs: clinical features and management // Dtsch. Arztebl. Int.-2012.-109, N 8.P. 133-140.

232. Hysing J., Wist E. Cardiotoxic effects of trastuzumab // Tidsskr. Nor. Laegeforen.-2011.-131, N 22.-P. 2239-2241.

233. O'Regan K. N., Jagannathan J. P., Ramaiya N., Hodi F. S. Radiologic aspects of immune-related tumor response criteria and patterns of immune-related adverse events in patients undergoing ipilimumab therapy // AJR Am. J. Roentgenol.-2011.-197, N 2.-W241-246.

234. Wolach O., Shpilberg O., Lahav M. Neutropenia after rituximab treatment: new insights on a late complication // Curr. Opin. Hematol.-2012.-19, N 1.-P. 32-38.

235. Brambilla G., Mattioli F., Robbiano L., Martelli A. Update of carcinogenicity studies in animals and humans of 535 marketed pharmaceuticals // Mutat. Res.-2011.-197, N 2.-P. 241-246.
236. Hail $W$. N. Forty years of translational cancer research // Cancer Discov.-2011.-1, N 5.-P. 383-390.

237. Todorovic-Rakovic N. Genome-based versus gene-based theory of cancer: possible implications for clinical practice // J. Biosci.-2011.-36, N 4.-P. 719-724.

238. Polyak K. Is breast tumor progression really linear? // Clin. Cancer Res.-2008.-14, N 2.-P. 339-341.

239. Fox E. J., Beckman R. A., Loeb L. A. Reply: is there any genetic instability in human cancer? // DNA Repair (Amst).-2010.-9, N 8.-P. 859-860.

240. Aktipis C. A., Kwan V. S., Johnson K. A., Neuberg S. L ., Maley C. C. Overlooking evolution: a systematic analysis of cancer relapse and therapeutic resistance research // PLoS One.-2011.-6, N 11.-e26100.

241. Longo D. L. Tumor heterogeneity and personalized medicine // N. Engl. J. Med.-2012.-366, N 10.-P. 956-957.

242. Navin N., Hicks J. Future medical applications of single-cell sequencing in cancer // Genome Med.-2011.-3, N 5.-P. 31.

Received 15.01.12 